\title{
Evaluation of a Rapid IgG4 Lateral Flow Dipstick Test to Detect Strongyloides stercoralis Infection in Northeast Thailand
}

\author{
Rahmah Noordin, ${ }^{1 *}$ Nor Suhada Anuar, ${ }^{1}$ Nor Mustaiqazah Juri, ${ }^{1}$ Phattharaphon Wongphutorn, ${ }^{2,5}$ Sirowan Ruantip, ${ }^{2}$ \\ Kulthida Y. Kopolrat, ${ }^{3,5}$ Chanika Worasith, ${ }^{3,5}$ Jiraporn Sithithaworn, ${ }^{4}$ and Paiboon Sithithaworn ${ }^{3,5}$ \\ ${ }^{1}$ Institute for Research in Molecular Medicine, Universiti Sains Malaysia, 11800 Penang, Malaysia; ${ }^{2}$ Biomedical Science Program, Graduate School, \\ Khon Kaen University, Khon Kaen, Thailand; ${ }^{3}$ Department of Parasitology, Faculty of Medicine, Khon Kaen University, Khon Kaen, Thailand; ${ }^{4}$ Faculty \\ of Medicine, Mahasarakham University, Mahasarakham, Thailand; ${ }^{5}$ Cholangiocarcinoma Research Institute (CARI), Khon Kaen University, Khon \\ Kaen, Thailand
}

\begin{abstract}
Strongyloides stercoralis affects more than half a billion people worldwide, and hyperinfection in immunocompromised patients can be fatal. Elimination of this neglected tropical disease requires field-applicable diagnostic tools. We conducted a laboratory evaluation of a lateral flow rapid dipstick test (SsRapid ${ }^{\mathrm{TM}}$ ) using sera samples from a Strongyloidesendemic area in northeast Thailand. Group 1 was S. stercoralis-positive and larvae- and/or antibody-positive (according to the lgG ELISA) $(N=100)$. Group 2 had negative fecal examination and IgG ELISA results $(N=25)$. Group 3 had other parasitic infections and negative IgG ELISA results $(N=25)$. The results showed good diagnostic sensitivity $(82 \%)$ and excellent specificity (96\%). Suggested improvements in the SsRapid ${ }^{\mathrm{TM}}$ test include increased diagnostic sensitivity and conversion to the more robust cassette format. Field studies should be performed as well.
\end{abstract}

Strongyloides stercoralis is the main causative agent of strongyloidiasis, a neglected tropical disease affecting 613.9 million people worldwide. ${ }^{1} \mathrm{~A}$ high prevalence of $\mathrm{S}$. stercoralis infection (as high as 61\%) has been reported in northeastern communities in Thailand. $^{2}$ The availability of a fieldapplicable rapid test is essential for epidemiological studies to assess its true prevalence and impact and to facilitate an elimination program. It is also beneficial for diagnosing patients in low-resource settings.

To date, there have been only three reports of the development of prototype lateral flow rapid tests for strongyloidiasis. $^{3-5}$ One of them, SsRapid ${ }^{\mathrm{TM}}$, is an IgG4 dipstick test lined with $S$. stercoralis recombinant proteins. ${ }^{5}$ The IgG4 level is significantly increased in individuals with chronic strongyloidiasis, and this level is higher in treatment-resistant patients. ${ }^{6,7}$ IgG4 is also known to be highly specific for the detection of strongyloidiasis and other helminth infections. Our previous study showed that the diagnostic specificity increased $13.3 \%$ when IgG4 replaced IgG as the secondary antibody used for an ELISA. ${ }^{8}$

The initial laboratory-based evaluation of SsRapid ${ }^{\mathrm{TM}}$ showed that its diagnostic sensitivity and specificity were $91.3 \%$ and $100 \%$, respectively. ${ }^{5}$ Further studies are needed to evaluate the diagnostic value of the rapid test and to suggest further improvements. Therefore, the present study aimed to evaluate SsRapid ${ }^{\mathrm{TM}}$ using serum samples collected from an endemic area in northeast Thailand.

The sample subjects recruited during this study were residents of a suburban area of Khon Kaen province, northeast Thailand. The map of the study area is available elsewhere. ${ }^{9}$

After the project protocols were explained, written informed consents were requested from the sample subjects. Blood and fecal samples were collected from the volunteers. Finally, 150 matched samples were used for the analysis during this study. Blood samples were collected by venipuncture. Fecal samples were collected in wide-mouth containers, kept at

*Address correspondence to Rahmah Noordin, Institute for Research in Molecular Medicine, Universiti Sains Malaysia, 11800 Penang, Malaysia. E-mail: rahmah8485@gmail.com ambient temperature, and transported to the laboratory. The study protocol for collecting and examining clinical samples was approved by the Ethics Committee of Khon Kaen University, Khon Kaen, Thailand (HE621073).

The participants were assigned to three groups based on fecal examination and serum based-IgG ELISA results (Table 1). Group 1 was S. stercoralis-positive and larvae- and/or antibodypositive (IgG ELISA) $(N=100)$. Group 1 was divided into group 1.1 (positive for larvae and antibody) and group 1.2 (positive for antibody). Group 2 was negative according to both testing methods $(N=25)$. Group 3 had other parasitic infections and negative lgG ELISA results $(N=25)$.

Fecal samples were processed to detect $S$. stercoralis larvae using the agar plate culture technique (APCT) and formalin-ethyl acetate concentration technique (FECT). ${ }^{10-12}$ When using the FECT, the results of triplicate examinations of each fecal sample were combined. The results of the sample were defined as positive if either the APCT or the FECT found at least one larva. The serum IgG ELISA using the $S$. ratti antigen was performed according to previously reported prototcols. $^{13,14}$

The dipsticks were prepared at the Institute for Research in Molecular Medicine, Universiti Sains Malaysia, as previously described. ${ }^{5}$ Mouse anti-human (Merck Millipore, Darmstadt, Germany) was conjugated to colloidal gold particles (optical density 10 at $530 \mathrm{~nm}) .{ }^{15}$ A volume of $25 \mu \mathrm{L}$ of the conjugate in drying buffer $\left(0.05 \mathrm{M} \mathrm{Na}_{2} \mathrm{HPO}_{4}, 1 \% \mathrm{w} / \mathrm{v}\right.$ bovine serum albu$\mathrm{min}, 0.1 \% \mathrm{w} / \mathrm{v} \mathrm{NaN}_{3}, 5 \% \mathrm{v} / \mathrm{v}$ trehalose) was added to the middle well of a triplet-well unit of a flat-bottomed ELISA microplate and dried at $35^{\circ} \mathrm{C}$. In a dry room ( $\approx 20 \%$ humidity), aluminum test pouches were prepared. Each pouch contained a dipstick, a triplet-well unit (wells A, B, C), and a desiccant. All pouches were sealed. One-hundred fifty rapid tests and two microplate well holders were couriered from Universiti Sains Malaysia to Khon Kaen University at room temperature. On arrival at Khon Kaen University, they were kept for approximately 2 months at $4^{\circ} \mathrm{C}$ before use.

The test was performed as reported previously. ${ }^{5}$ Briefly, two drops of buffer A were placed into well C, and $25 \mu \mathrm{L}$ of buffer B was pipetted in well B to reconstitute the dried IgG4-gold. In well $A$, serum $(10 \mu \mathrm{L})$ was mixed with an equal volume of buffer 
TABLE 1

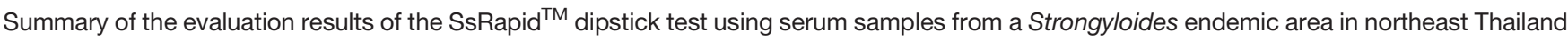

\begin{tabular}{|c|c|c|c|c|c|}
\hline \multirow[b]{2}{*}{ Group } & \multirow[b]{2}{*}{ Assessed, $\mathrm{n}$} & \multicolumn{2}{|c|}{ SsRapid ${ }^{\mathrm{TM}}$ reactivity } & \multirow[b]{2}{*}{ Sensitivity (\%) } & \multirow[b]{2}{*}{ Specificity (\%) } \\
\hline & & Positive & Negative & & \\
\hline Group 1 Positive S. stercoralis & 100 & 82 & 18 & & \\
\hline 1.1 Positive S. stercoralis larvae and antibody & 84 & 69 & 15 & $69 / 84(82)$ & \\
\hline 1.2 Positive S. stercoralis antibody & 16 & 13 & 3 & & \\
\hline Group 2 Negative in endemic areas & 25 & 6 & 19 & & \\
\hline Group 3 Other parasites & 25 & 1 & 24 & & $24 / 25(96)$ \\
\hline Echinostoma sp. & 1 & 0 & 1 & & \\
\hline Hookworm & 9 & 1 & 8 & & \\
\hline Minute intestinal fluke & 1 & 0 & 1 & & \\
\hline Opisthorchis viverrini & 7 & 0 & 7 & & \\
\hline Taenia sp. & 1 & 0 & 1 & & \\
\hline Minute intestinal fluke + hookworm & 1 & 0 & 1 & & \\
\hline O. viverrini + hookworm & 1 & 0 & 1 & & \\
\hline O. viverrini + minute intestinal fluke & 1 & 0 & 1 & & \\
\hline O. viverrini + Taenia sp. & 2 & 0 & 2 & & \\
\hline O. viverrini + minute intestinal fluke + Echinostoma sp. & 1 & 0 & 1 & & \\
\hline
\end{tabular}

Group 1: Positive for S. lanve and/or antibody (S. ratti ELISA) Cutoff: 132 units.

Group 2: Negative for $S$. stercoralis antibody and fecal examination. This group resides in endemic areas.

Group 3: Positive for other parasites according to the fecal examination (formalin-ethyl acetate concentration technique) results.

The positive and negative predictive values of the SsRapid are $98.6 \%$ and $61.5 \%$, respectively, and the accuracy is $85.3 \%$. The receiver-operating characteristic curve shows an area under the curve of 0.8303 to $0.9631(P<0.0001)$ (Supplemental Figure S5).

B. After the mixture migrated up the dipstick, it was transferred to well B. When the IgG4-gold conjugate was fully absorbed, the dipstick was transferred to well $\mathrm{C}$ for a washing step. After approximately 10 minutes, the background cleared and the dipstick result was read: two red lines (control and test lines) on the dipstick indicate a positive result, and one red control line denotes a negative result. Several documents, including a quick procedure guide (flow chart), an instruction sheet, a video of how to perform the test, a dipstick line intensity chart, and images of some dipstick results, were sent via e-mail to Professor Sithithaworn at Khon Kaen University (Supplemental Figures S1, S2, S3, and S4).

Table 1 shows the evaluation results. The positive and negative results were converted into binary data for Receiver Operating Characteristic (ROC) analysis using GraphPad Prism version 8.0.2. The area under the curve (AUC) is 0.8303 to 0.9631 ( $P<0.0001$ ) (Supplemental Figure S5). The diagnostic sensitivity of SsRapid ${ }^{\mathrm{TM}}$ based on the serum samples (larvae-positive, IgG-positive) of group 1.1 was $82 \%(69 / 84)$, and the diagnostic specificity based on the serum samples (other parasitic infections, IgG-negative) of group 3 was $96 \%$ (24/25). The positive and negative predictive values were $98.6 \%$ and $61.5 \%$, respectively, and the accuracy was $85.3 \%$.

SsRapid $^{\mathrm{TM}}$ was positive for $81.3 \%(13 / 16)$ of group 1.2 serum samples (larvae-negative, IgG-positive). The IgG4 rapid test was positive for $24 \%(6 / 25)$ of group 2 sera from apparently healthy people from a Strongyloides-endemic area. The group 2 samples were excluded from the diagnostic specificity determination because some group members may have been infected but asymptomatic and IgG-negative. An analysis of the $\operatorname{lgG}$ antibody levels and positive rates found by the lgG4 dipstick revealed a statistically significant positive association (chi-square test, $P<0.05$ ) (Supplemental Table S6). Figure 1 shows the representative images of the dipstick results.

Table 2 shows a comparison of the results and parameters of the present study and the other reported studies using lateral flow rapid tests for strongyloidiasis. The diagnostic specificity of the cassette tests using larvae extract or S. stercoralis

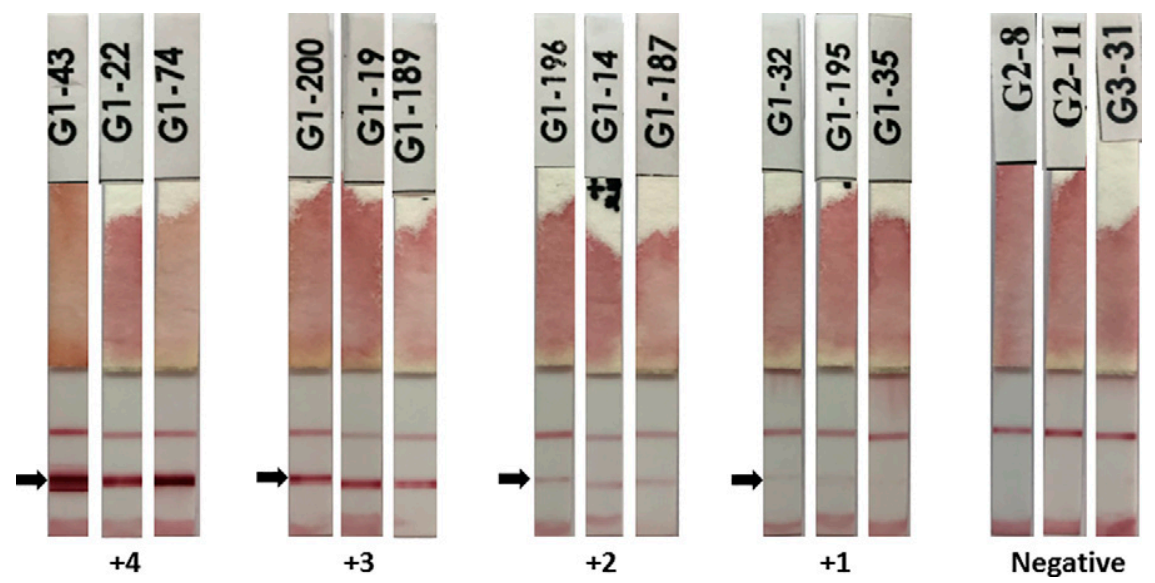

FIGURE 1. Representative images of the SsRapid ${ }^{\mathrm{TM}}$ dipstick results. The arrow shows the test line. The control line is above the test line. The reddish color at the bottom end of the dipstick, which may appear like a line, is the stain of the lgG4-gold conjugate; therefore, it is ignored when reading the results. This figure appears in color at www.ajtmh.org. 
TABLE 2

Studies of lateral flow rapid tests for the detection of Strongyloides stercoralis infection

\begin{tabular}{|c|c|c|c|c|c|c|c|c|c|c|}
\hline No. & Format & Antigen & $\begin{array}{l}\text { Detecting } \\
\text { antibody (gold- } \\
\text { conjugated) }\end{array}$ & $\begin{array}{l}\text { Sample } \\
\text { dilution }\end{array}$ & $\begin{array}{l}\text { Diagnostic } \\
\text { sensitivity }\end{array}$ & $\begin{array}{l}\text { Diagnostic } \\
\text { specificity }\end{array}$ & $\begin{array}{l}\text { Positive and } \\
\text { negative } \\
\text { predictive } \\
\text { values }\end{array}$ & $\begin{array}{l}\text { Intensity } \\
\text { reading } \\
\text { chart }\end{array}$ & Location & Reference \\
\hline $1 a$ & Cassette & $\begin{array}{l}\text { Recombinant } \\
\text { protein (SsIR) }\end{array}$ & $\lg G$ & $1: 100$ & $91.7 \%(55 / 60)$ & $\begin{array}{c}83.8 \%(88 / \\
105)\end{array}$ & $\begin{array}{l}76.4 \% \\
94.6 \%\end{array}$ & $\begin{array}{l}\text { Nine line } \\
\text { intensity } \\
\text { levels, 8-0.5; } \\
\text { cutoff inten- } \\
\text { sity level } \geq 1\end{array}$ & Thailand & $\begin{array}{c}\text { Boonroumkaew } \\
\text { et al. (2020) }\end{array}$ \\
\hline $1 b$ & Cassette & $\begin{array}{l}\text { Recombinant } \\
\text { protein (SsIR) }\end{array}$ & $\lg G 4$ & $1: 100$ & $78.3 \%(47 / 60)$ & $\begin{array}{c}84.8 \%(89 / \\
105)\end{array}$ & $\begin{array}{l}76.4 \% \\
87.3 \%\end{array}$ & $\begin{array}{l}\text { Nine line } \\
\text { intensity } \\
\text { levels, 8-0.5; } \\
\text { cutoff inten- } \\
\text { sity level } \geq 0.5\end{array}$ & Thailand & $\begin{array}{c}\text { Boonroumkaew } \\
\text { et al. (2020) }\end{array}$ \\
\hline 2 & Cassette & $\begin{array}{l}\text { Larvae extract of } \\
\text { Strongyloides } \\
\text { stercoralis }\end{array}$ & $\lg G$ & $1: 50$ & $93.3 \%(56 / 60)$ & $\begin{array}{c}83.7 \%(87 / \\
104)\end{array}$ & $\begin{array}{l}76.7 \% \\
95.6 \%\end{array}$ & $\begin{array}{l}\text { Nine line } \\
\text { intensity } \\
\text { levels, 8-0.5; } \\
\text { cutoff inten- } \\
\text { sity level } \geq 0.5\end{array}$ & Thailand & $\begin{array}{l}\text { Sadaow et al. } \\
(2020)\end{array}$ \\
\hline 3 & Dipstick & $\begin{array}{l}\text { Recombinant } \\
\text { proteins (rNIE } \\
\text { and rSs1a) }\end{array}$ & $\lg G 4$ & $1: 2$ & $91.3 \%(21 / 23)$ & $100 \%(82 / 82)$ & $\begin{array}{r}100 \% \\
7.6 \%\end{array}$ & $\begin{array}{l}\text { Intensity of the } \\
\text { test line was } \\
\text { quantified } \\
\text { using image } \\
\text { analysis } \\
\text { software }\end{array}$ & Malaysia & $\begin{array}{l}\text { Yunus et al. } \\
\text { (2019) }\end{array}$ \\
\hline 4 & Dipstick & $\begin{array}{l}\text { Recombinant } \\
\text { proteins (rNIE } \\
\text { and rSs1a) }\end{array}$ & $\lg G 4$ & $1: 2$ & $82 \%(69 / 84)$ & $96 \%(24 / 25)$ & $\begin{array}{l}98.6 \% \\
61.5 \%\end{array}$ & $\begin{array}{l}\text { Four intensity } \\
\text { scores for } \\
\text { positive } \\
\text { results: }+1 \text { to } \\
\quad+4 ; \text { negative } \\
\text { result: no test } \\
\text { line }\end{array}$ & Thailand & Present study \\
\hline
\end{tabular}

SsIR $=$ S. stercoralis immunoreactive recombinant antigen. All evaluation studies except study 4 were performed at the location where the tests were developed.

immunoreactive (SsIR) recombinant antigen protein was approximately $84 \%$ to $85 \%$. The diagnostic sensitivity of the rapid IgG cassette tests using larvae extract and $S$. stercoralis immunoreactive recombinant antigen protein were similar ( $91.7 \%$ and $93.3 \%$, respectively). The sensitivity rates were higher than that of the IgG4 cassette rapid test (78.3\%) using the same recombinant protein., ${ }^{3,4}$ Strongyloides IgG4 antibody levels are increased during chronic infection, whereas $\operatorname{lgG}$ is detected with both acute and chronic strongyloidiasis. ${ }^{7}$ Therefore, it is not surprising that, generally, the infection prevalence detected by $\lg \mathrm{G}$ is higher than that detected by IgG4.

SsRapid $^{\mathrm{TM}}$ is an IgG4 test. The first evaluation study was performed in-house (at Universiti Sains Malaysia) using positive samples from Malaysia, and it showed high diagnostic sensitivity (91.3\%) and specificity (100\%). During the present study, SsRapid ${ }^{\mathrm{TM}}$ was evaluated using serum samples from a northeast Thailand endemic area. The results showed reduced diagnostic sensitivity (82\%), but the specificity remained high (96\%). Whether the reduced sensitivity can be attributed to the fact that the Strongyloides serum samples were from a different country or to technical issues must be investigated. The dipstick format requires two pipetting steps and moving the dipstick from well to well. Therefore, it may be more prone to technical inconsistency than a cassette test format with a much simpler procedure. Nevertheless, the diagnostic sensitivity of SsRapid ${ }^{\mathrm{TM}}$ during the present study $(82 \%)$ was slightly higher than that of the lgG4 cassette test (78.3\%) as reported by Boonroumkaew et al. ${ }^{2}$ There was no cross-reactivity with Opisthorchis viverrini and other parasites (Taenia, minute intestinal flukes, and Echinostome) in northeast Thailand. A cross-reaction with hookworms (1 of 9 cases) was observed. In northeast Thailand, Strongyloides and O. viverrini are the two most common parasites, followed by a very low prevalence of the other helminth infections (Table 1). To date, there has been no report of Schistosoma in the area; therefore, they were not included in the specificity evaluation. During our previous study performed at the Universiti Sains Malaysia, 11 schistosomiasis sera were negative when tested with the rapid dipstick test. ${ }^{5}$ Other notable results from this study were the significant area under the curve of the receiveroperating characteristic curve, significant correlation between the IgG ELISA units and SsRapid ${ }^{\mathrm{TM}}$ positive rates, and good test accuracy.

A simpler and more robust cassette format of SsRapid ${ }^{\mathrm{TM}}$ needs to be developed. The diagnostic sensitivity should be at least $90 \%$ when tested with samples from larvae-positive individuals, and the diagnostic specificity should remain higher than $95 \%$. Some of the samples with false-negative results during the present evaluation will be used to optimize the SsRapid ${ }^{\text {TM }}$ cassette test to help improve its diagnostic sensitivity. Afterwards, it should be evaluated at Khon Kaen University and other places, and during field studies. The test should also work well with whole blood and eluted blood samples to make it field-applicable.

Near the end of a disease elimination program, the infection prevalence is low; therefore, a diagnostic test with high specificity is crucial to support decisions to stop mass drug administration. ${ }^{16}$ The high specificity of SsRapid ${ }^{\mathrm{TM}}$ may indicate its suitability for such use in the future.

Received March 17, 2021. Accepted for publication May 10, 2021.

Published online July 8, 2021. 
Note: Supplemental table and figures appear at www.ajtmh.org.

Acknowledgments: This study was funded by grants from the Malaysian Ministry of Higher Education (MOHE) MyLab grant 1/2018 (no 203.CIPPM.673014 2) and Fluke Free Thailand, National Research Council of Thailand. We also acknowledge support from MOHE's Institution Centre of Excellence (HICoE) program (no: 311/CIPPM/ 4401005).

Authors' addresses: Rahmah Noordin, Nor Suhada Anuar, and Nor Mustaiqazah Juri, Universiti Sains Malaysia, Institute for Research in Molecular Medicine, Institute for Research in Molecular Medicine, Universiti Sains Malaysia, Minden, Penang, Malaysia 11800, E-mails: rahmah8485@gmail.com, norsuhada@usm.my, and mustaiqazah@ yahoo.com. Phattharaphon Wongphutorn, Khon Kaen University, Biomedical Science Program Graduate School, Khon Kaen, Thailand and Khon Kaen University, Cholangiocarcinoma Research Institute (CARI), Nai Mueang, Khon Kaen, Thailand, E-mail: phat phutorn@ hotmail.com. Sirowan Ruantip, Khon Kaen University, Biomedical Science Program, Graduate School, Nai Mueang, Khon Kaen, Thailand, E-mail: sirowan.r@kkumail.com. Kulthida Y. Kopolrat, Chanika Worasith, and Paiboon Sithithaworn, Khon Kaen University, Parasitology, Khon Kaen, Thailand, and Khon Kaen University, Cholangiocarcinoma Research Institute (CARI), Nai Mueang, Khon Kaen, Thailand, E-mails: kulthida_kop@yahoo.com, chanika.w@ kkumail.com, and paibsit@gmail.com. Jiraporn Sithithaworn, Mahasarakham University, Faculty of Medicine, Mahasarakham, Thailand, E-mail: jirapornsith@gmail.com.

\section{REFERENCES}

1. Buonfrate D et al., 2020. The global prevalence of Strongyloides stercoralis infection. Pathogens 9: 468.

2. Jongsuksuntigul P, Intapan PM, Wongsaroj T, Nilpan S, Singthong S, Veerakul S, Maleewong W, 2003. Prevalence of Strongyloides stercoralis infection in northeastern Thailand (agar plate culture detection). J Med Assoc Tha 86: 737-741.

3. Boonroumkaew P, Sadaow L, Sanpool O, Rodpai R, Thanchomnang T, Phupiewkham W, Intapan PM, Maleewong W, 2020. Effectiveness of Strongyloides recombinant IgG immunoreactive antigen in detecting $\operatorname{lgG}$ and IgG4 subclass antibodies for diagnosis of human strongyloidiasis using rapid immunochromatographic tests. Diagnostics (Basel) 10: 615.

4. Sadaow L, Sanpool O, Rodpai R, Boonroumkaew P, Maleewong W, Intapan PM, 2020. Development of immunochromatographic device as a point-of-care tool for serodiagnosis of human strongyloidiasis cases. Eur $\mathrm{J}$ Clin Microbiol Infect Dis 39: 465-470.

5. Yunus MH, Arifin N, Balachandra D, Anuar NS, Noordin R, 2019. Lateral flow dipstick test for serodiagnosis of strongyloidiasis. Am J Trop Med Hyg 101: 432-435.
6. Satoh M, Toma H, Sato Y, Kikuchi M, Takara M, Shiroma Y, Kiyuna S, Hirayama K, 1999. Production of a high level of specific IgG4 antibody associated with resistance to albendazole treatment in HLA-DRB1*0901-positive patients with strongyloidiasis. Am J Trop Med Hyg 61: 668-671.

7. Arifin N, Hanafiah KM, Ahmad H, Noordin R, 2019. Serodiagnosis and early detection of Strongyloides stercoralis infection. $J$ Microbiol Immunol Infect 52: 371-378.

8. Norsyahida A, Riazi M, Sadjjadi SM, Muhammad Hafiznur Y, Low HC, Zeehaida M, Noordin R, 2013. Laboratory detection of strongyloidiasis: IgG-, IgG4 - and IgE-ELISAs and crossreactivity with lymphatic filariasis. Parasite Immunol 35: 174179.

9. Sithithaworn P, Yongvanit P, Duenngai K, Kiatsopit N, Pairojkul C, 2014. Roles of liver fluke infection as risk factor for cholangiocarcinoma. J Hepatobiliary Pancreat Sci 21: 301-308.

10. Koga K, Kasuya S, Khamboonruang C, Sukhavat K, leda M, Takatsuka N, Kita K, Ohtomo H, 1991. A modified agar plate method for detection of Strongyloides stercoralis. Am J Trop Med Hyg 45: 518-521.

11. Elkins DB, Haswell-Elkins MR, Mairiang E, Mairiang P, Sithithaworn P, Kaewkes S, Bhudhisawasdi V, Uttaravichien T, 1990. A high frequency of hepatobiliary disease and suspected cholangiocarcinoma associated with heavy Opisthorchis viverrini infection in a small community in north-east Thailand. Trans $R$ Soc Trop Med Hyg 84: 715-719.

12. Sithithaworn $P$, Srisawangwong $T$, Tesana $S$, Daenseekaew W, Sithithaworn J, Fujimaki Y, Ando K, 2003. Epidemiology of Strongyloides stercoralis in north-east Thailand: application of the agar plate culture technique compared with the enzymelinked immunosorbent assay. Trans $R$ Soc Trop Med Hyg 97: 398-402.

13. Eamudomkarn C, Sithithaworn P, Sithithaworn J, Kaewkes S, Sripa B, Itoh M, 2015. Comparative evaluation of Strongyloides ratti and S. stercoralis larval antigen for diagnosis of strongyloidiasis in an endemic area of opisthorchiasis. Parasitol Res 114: 2543-2551.

14. Eamudomkarn C et al., 2018. Diagnostic performance of urinary IgG antibody detection: A novel approach for population screening of strongyloidiasis. PLoS One 13: e0192598.

15. Makhsin SR, Razak KA, Noordin R, Zakaria ND, Chun TS, 2012. The effects of size and synthesis methods of gold nanoparticle-conjugated M $\alpha \mathrm{HlgG} 4$ for use in an immunochromatographic strip test to detect brugian filariasis. Nanotechnology 23: 495719.

16. Gass K, 2020. Time for a diagnostic sea-change: Rethinking neglected tropical disease diagnostics to achieve elimination. PLoS Negl Trop Dis 14: e0008933. 